\title{
Induction of Topographical Changes in Poly- $\varepsilon$-Caprolactone Scaffolds for Bone Tissue Engineering: Biocompatibility and Cytotoxicity Evaluations
}

\author{
Ana Laura Alfano and Juan Manuel Fernandez* \\ LIOMM (Laboratorio de Investigación en Osteopatías y Metabolismo Mineral) - Departamento de Ciencias Biológicas, \\ Facultad de Ciencias Exactas, Universidad Nacional de La Plata, 1900 La Plata, Argentina
}

\begin{abstract}
Bone tissue engineering (BTE) uses principles from different fields, such as medicine, biochemistry and engineering, in order to restore or improve damaged tissue. Topographic changes of Poly- $\varepsilon$ caprolactone scaffolds $(\mathrm{PCL})$ have been previously induced by exposure of the polymer to various concentrations of $\mathrm{NaOH}$ for different periods of time. However, lack of consistency between the treatment conditions used by different research groups has led to inconsistent results, with no clear conclusion arising regarding the benefits of these treatments. The aim of this study was to evaluate how different treatments (time-concentration) with $\mathrm{NaOH}$ could affect its biocompatibility for bone marrow stromal cells (BMSC) and its cytotoxicity towards RAW 264.7 macrophages of a PCL scaffold. We also analyzed the physicochemical and mechanical properties of the PCL films after different treatment. We have shown that treatment with for 2 hours with $\mathrm{NaOH}$ produced changes that affected the hydrophobicity and biocompatibility of the scaffold by increasing the proliferation and ALP activity in cells grown on them. Beside, 24 hours of treatment with $\mathrm{NaOH}$ produced significant decreased in mechanical properties resulting in a scaffold highly fragile and low biocompatibility compared to PCL. Therefore, treatment for 2 hours with $\mathrm{NaOH}$ can be used to increase the biocompatibility of PCL scaffolds.
\end{abstract}

Keywords: Cytotoxicity, Bone Tissue Engineering, Bone Marrow Stromal Cells, RAW 264.7 Macrophages, Poly-Epsilon-Caprolactone.

\section{INTRODUCTION}

Most available options to replace or restore extensively damaged bone tissue are not effective. Metals have low osteointegration, ceramics are brittle and bone grafts have several disadvantages including low availability due to insufficient donors, graft rejection and disease transmission. Furthermore, in view of overall population growth and increasing life expectancy, the burden of bone lesions will continue growing over the next years. ${ }^{1-4}$

Bone tissue engineering (BTE) uses concepts from different fields, such as medicine, biochemistry and engineering, in order to restore or improve damaged tissue. ${ }^{5}$ Different polymer-based scaffolds have been developed for use in BTE. ${ }^{6-10}$ These materials must meet many requirements for their application in BTE, such as biocompatibility, low toxicity, adequate mechanical properties and

\footnotetext{
${ }^{*}$ Author to whom correspondence should be addressed.
}

biodegradation rates. ${ }^{11}$ Although these requirements are greatly dependent on the chemical structure of the material, other properties may also be important. For example, three-dimensional and topographic changes could alter the behaviour of bone cells grown on a scaffold.

Many research groups ${ }^{12,13}$ including ours ${ }^{14,15}$ have demonstrated through in vitro studies that topographic changes of scaffolds can affect cellular activity. Poly$\varepsilon$-caprolactone (PCL) is a polyester that has been widely studied for scaffold design, and is currently FDA-approved.

PCL-scaffolds have been previously induced by exposure of the polymer to various concentrations of $\mathrm{NaOH}$ for different periods of time topographic changes. ${ }^{16-19}$ However, lack of consistency between the treatment conditions used by different research groups has led to inconsistent results, with no clear conclusion arising regarding the benefits of these treatments on the biocompatibility of the 
scaffolds. Tan and $\mathrm{Teoh}^{16}$ have postulated that the ester groups of PCL could be hydrolyzed by $\mathrm{NaOH}$ (Scheme 1) with generation of hydroxycaproic acid, thus modifying the scaffold's hydrophobicity.

The aim of this study was to evaluate how different treatments of a PCL-based scaffold could affect its biocompatibility for bone marrow stromal cells (BMSC) and its cytotoxicity towards RAW 264.7 macrophages. This cell line is highly sensitive to cytotoxic agents and responds by sharply increasing pro-inflammatory cytokines such as interleukin-1 (IL-1) and tumor necrosis factoralpha (TNF- $\alpha$ ) as well as the production of nitric oxide (NO). Due to these features, macrophages in culture constitute an excellent model for cytotoxicity studies with various substances in biological systems. ${ }^{14,20-23}$ In addition, changes in hydrophobicity and mechanical properties were evaluated, and correlated with cellular studies.

\section{MATERIALS AND METHODS}

\subsection{Preparation of PCL Films}

Poly- $\varepsilon$-caprolactone (PCL) was purchased from Aldrich. The manufacturer reports its weight average molecular weight $(\mathrm{Mw})$ and polydispersity index $(\mathrm{PI})$ to be $65000 \mathrm{~g} \cdot \mathrm{mol}^{-1}$ and 1.4 , respectively. Films were prepared by the casting method. Briefly, PCL was dissolved in chloroform and casted into a glass Petri dish. The solvent was allowed to evaporate at room temperature and then the resulting films were dried under vacuum until constant weight.

PCL films were then cut and treated with different concentrations of $\mathrm{NaOH}$ for various periods of time. Some membranes were submitted to $2 \mathrm{~N} \mathrm{NaOH}$ for either 1 or 2 hours $(1 \mathrm{H}-2 \mathrm{~N}$ and $2 \mathrm{H}-2 \mathrm{~N}$ respectively). Other films were treated with $4 \mathrm{~N} \mathrm{NaOH}$ for 1,2 or 24 hours $(1 \mathrm{H}-4 \mathrm{~N}$, $2 \mathrm{H}-4 \mathrm{~N}$ and $24 \mathrm{H}-4 \mathrm{~N}$ respectively).

After these treatments, the different films were washed with water several times to ensure removal of all $\mathrm{NaOH}$, and sterilized by UV exposure for $2 \mathrm{~h} \cdot{ }^{15,20}$

\subsection{Characterization of Scaffolds}

\subsubsection{Molecular Weight and Polydispersity Index}

To check if the different treatments affect the Mw and molecular weight distribution of the polymers, these were determined by size exclusion chromatography (SEC),

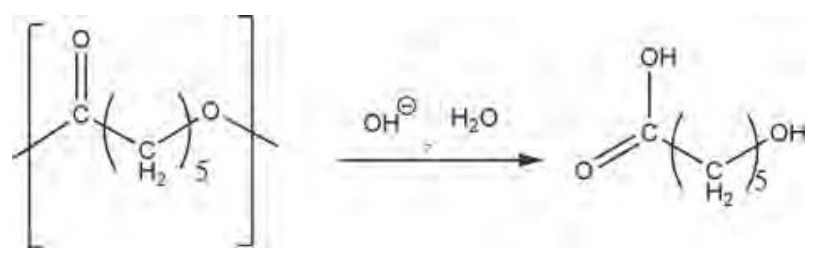

Scheme 1. Hydrolysis reaction of PCL with $\mathrm{NaOH}$ producing hydroxycaproic acid. using an LKB-2249 instrument at $25{ }^{\circ} \mathrm{C}$. A series of $\mu$-Styragel columns, pore sizes $10^{5}, 10^{4}, 500$ and $100 \AA$, were used with chloroform as an eluent. The polymer concentration was $4-5 \mathrm{mg} / \mathrm{ml}$ and the flow rate was $0.5 \mathrm{ml} / \mathrm{min}$. The polymer was detected at $5.75 \mu \mathrm{m}$ with a Miran $1 \mathrm{~A}$ infrared spectrophotometer detector and calibration was performed using poly(methyl methacrylate) as a standard.

\subsubsection{Topographic Changes}

Possible changes in the topography of scaffolds as a consequence of their treatment with $\mathrm{NaOH}$ were evaluated using scanning electron microscopy (SEM; Phillips 505, The Netherlands), with an accelerating voltage of $20 \mathrm{kV}$. The images were analysed by Soft Imaging System ADDAII.

\subsubsection{Water Contact Angle}

Water contact angle measurements of the films were carried out as described previously. ${ }^{7}$ All tests were performed on the air-facing surface of samples. For each sample, six measurements were performed on different points in order to calculate the mean static contact angle.

\subsubsection{Elastic Modulus}

The elastic modulus of each sample was evaluated at room temperature using a universal testing machine (Digimess TC500) equipped with force load cells of $50 \mathrm{~N}$ capacity ("Interface" of Arizona, USA). The dog bone-shaped specimens $\left(50 \times 18 \mathrm{~mm}^{2}\right)$ were tested at a rate of $5 \mathrm{~mm} / \mathrm{min}$ until breaking point. ${ }^{15}$ Elastic modulus was calculated from tensile stress-strain curves.

\subsection{Biocompatibility Studies with Bone Marrow Stromal Cells (BMSC)}

BMSC were obtained from rats as described previously. ${ }^{24}$ These cells are characterized by their ability to differentiate into various phenotypes, such as osteoblasts, adipocytes or chondrocytes, given the right stimuli. ${ }^{20,24}$ Briefly, young male Wistar rats were sacrificed under anesthesia by rapid neck dislocation. BMSC were collected by flushing the dissected femoral and tibial diaphysis medullary canal with DMEM (Invitrogen, Buenos Aires, Argentina) under sterile conditions. The resulting suspension was seeded in a $25 \mathrm{~cm}^{2}$ tissue culture flask. Adhering cells were grown in DMEM supplemented with $5 \%(\mathrm{v} / \mathrm{v})$ FBS and antibiotics $(100 \mathrm{U} / \mathrm{ml}$ penicillin and $100 \mathrm{~g} / \mathrm{ml}$ streptomycin) in a humidified atmosphere of $95 \%$ air and $5 \% \mathrm{CO}_{2}$. For the experiments, polymeric films were cut to size and placed inside wells of a 24-well plate. BMSC were resuspended and replated on each film slice at a density of $5 \times 10^{4}$ cells/well, and cultured in $10 \%$ FBS-DMEM at $37{ }^{\circ} \mathrm{C}$. After cells reached confluence, they were induced to differentiate into osteoblasts using an osteogenic medium (DMEM$10 \%$ FBS containing $25 \mathrm{mg} / \mathrm{mL}$ ascorbic acid and $5 \mathrm{mM}$ 
sodium-glycerol-phosphate), which was changed twice a week. Osteoblastic differentiation was evaluated by measuring alkaline phosphatase activity (ALP). After 14 and 21 days of osteogenic differentiation, cell monolayers were washed with phosphate-buffered saline (PBS) and the total cell extract was obtained with $200 \mathrm{~L} 0.1 \%$ Triton-X100. A $100 \mathrm{~L}$ aliquot of the extract was used to evaluate ALP by hydrolysis of $p$-nitrophenylphosphate ( $p$-NPP) into $p$-nitrophenol ( $p$-NP) at $37{ }^{\circ} \mathrm{C}$ for 1 hour. The absorbance of $p$-NP was recorded at $405 \mathrm{~nm} .{ }^{25}$ Aliquots of each cell extract were used for protein determination by Bradford's technique. ${ }^{26}$

Transcription factor Runx-2 expression by western blot analysis was studied. BMSC were grown onto scaffolds in DMEM-10\% FBS and then differentiated into osteoblasts as described above. After 21 days in osteogenic medium, cells were lysed in Laemmli's buffer. ${ }^{15}$ These lysates were heated to $100{ }^{\circ} \mathrm{C}$ for $3 \mathrm{~min}$, and $30 \mu \mathrm{g}$ protein subjected to $12 \%$ SDS-PAGE. The separated proteins were then transferred to PVDF membranes. After washing and blocking, the membranes were incubated overnight at $4{ }^{\circ} \mathrm{C}$ with an antibody directed against Cbfa-1/Runx-2 (Santa Cruz Biotechnology, Santa Cruz, CA, USA) for evaluation of osteoblastogenesis. ${ }^{15,27}$ In order to normalize the results, all blots were stripped and reprobed with an anti- $\beta$-actin antibody (Sigma, St.Louis, MO, USA). Blots were developed by an enhanced chemiluminescence method. The intensity of the specific bands was quantified by densitometry after scanning of the photographic film. Images were analysed using the gels plugin of MBF_Image $\mathbf{J}$ (http://www.macbiophotonics.ca).

Alternatively, growth of BMSC on the scaffolds was estimated using a colorimetric tetrazolium assay. This assay measures the reduction of the tetrazolium salt 3-(4,5-dimethylthiazol-2-yl)-2,5-diphenyl tetrazolium bromide (MTT) to formazan by intact mitochondria in living cells. Thus, absorbance change is directly proportional to the number of viable cells. ${ }^{20}$ For this assay, $3 \times 10^{4}$ BMSC were plated in a 48-multiwell plate (with a polymer film placed in each well) and cultured for 2, 24, 96 and 168 hours in $10 \%$ FBS-DMEM at $37^{\circ} \mathrm{C}$. The medium was removed, cells were washed with PBS and fresh medium containing the MTT reagent (Sigma, USA) at a final concentration of $1 \mathrm{mg} / \mathrm{mL}$ was added. After a 3-hour incubation each film was removed, placed in a new 48-multiwell plate and washed again with PBS. Color was developed by addition of $200 \mathrm{~L}$ dimethylsulfoxide (DMSO) (Merck, Argentina) and mixing in a plate shaker for 20 minutes, after which absorbance was measured at $540 \mathrm{~nm} \cdot{ }^{20}$

In order to evaluate the morphology and cellular interactions of BMSC growing on different scaffolds, we carried out immunofluorescent staining of the actin cytoskeleton and the nucleus. Briefly, BMSC were grown on the polymeric films for 5 days, washed with PBS and fixed with 4\% $p$-formaldehyde for $10 \mathrm{~min}$. Cell membranes were then permeabilized with cold ethanol. After blocking with 10\%FBS for 2 hours, 1:100 Alexa fluor dye in PBS was added for 2 hours (Molecular Probe, Invitrogen, USA) to stain actin filaments. Films were then placed on slides, propidium iodide added in order to stain nuclei, and observed with a fluorescence microscope.

\subsection{Cytotoxicity Studies with RAW 264.7 Macrophages}

Murine macrophage RAW 264.7 cells were grown in DMEM supplemented with 5\% (v/v) FBS and antibiotics (100 U/ml penicillin and $100 \mathrm{~g} / \mathrm{ml}$ streptomycin) in a humidified atmosphere of $95 \%$ air and $5 \% \mathrm{CO}_{2}$. For the experiments, polymeric films were cut to size, inserted in a 24-well plate and macrophages plated on them.

Nitric oxide (NO) production was assessed using Griess' reaction $^{20,27-29}$ (using sulfanilic acid as the diazotizing agent and $N$-1-napthylethylene diamine as the coupling agent). The stable end-product of NO and nitrite released into the culture medium by RAW 264.7 cells was measured after 72, 96 and 168 hours of culture. Briefly, $400 \mu \mathrm{l}$ samples of conditioned media or nitrite standards $(0-100 \mathrm{nM})$ were mixed with $400 \mu \mathrm{l}$ of Griess' reagent ( $1 \%$ sulfanilamide and $0.1 \%$ naphthylethylene-diamine in $5 \%$ phosphoric acid) and absorbance was measured at $530 \mathrm{~nm}$ against a blank prepared with non-conditioned culture medium.

The pro-inflammatory cytokines tumor necrosis factor alpha (TNF- $\alpha$ ) and interleukin-1 (IL-1) released into the culture medium by RAW 264.7 cells were evaluated at 72,96 and 168 hours by ELISA kits (Mouse IL- $1 \beta$ ELISA Set, BD Biosciences OptEIA ${ }^{\mathrm{TM}}$ and TNF- $\alpha$ kits Mouse ELISA Set, BD Biosciences OptEIA ${ }^{\mathrm{TM}}$ ) following the manufacturer's instructions, as we have previously described ${ }^{14,20}$ using a calibration curve from 2 to $240 \mathrm{pg} / \mathrm{ml}$.

For NO and pro-inflammatory cytokine production, RAW 264.7 cells were also plated on standard culture tissue dishes with or without lipopolysaccharide (LPS, $0.1 \mathrm{~g} / \mathrm{ml}$ ) as positive and negative controls, respectively.

\subsection{Statistical Analysis}

Student's $t$-test was used for comparisons between control and experimental groups. All results are expressed as mean \pm S.E.M. and represent at least three different experiments performed in triplicate.

\section{RESULTS AND DISCUSSION}

To obtain conclusive results, in the present study we prepared films of PCL and treated them with different concentrations of $\mathrm{NaOH}(2$ and $4 \mathrm{~N})$ for either 1 or 2 hours. In addition, we treated PCL films with $4 \mathrm{~N} \mathrm{NaOH}$ for a longer period (24 hours). Figures 1(A)-(F) shows SEM images of the surface of PCL scaffolds before and after treatments with $\mathrm{NaOH}$. 2-hour (D), (E) and 24-hour (F) 

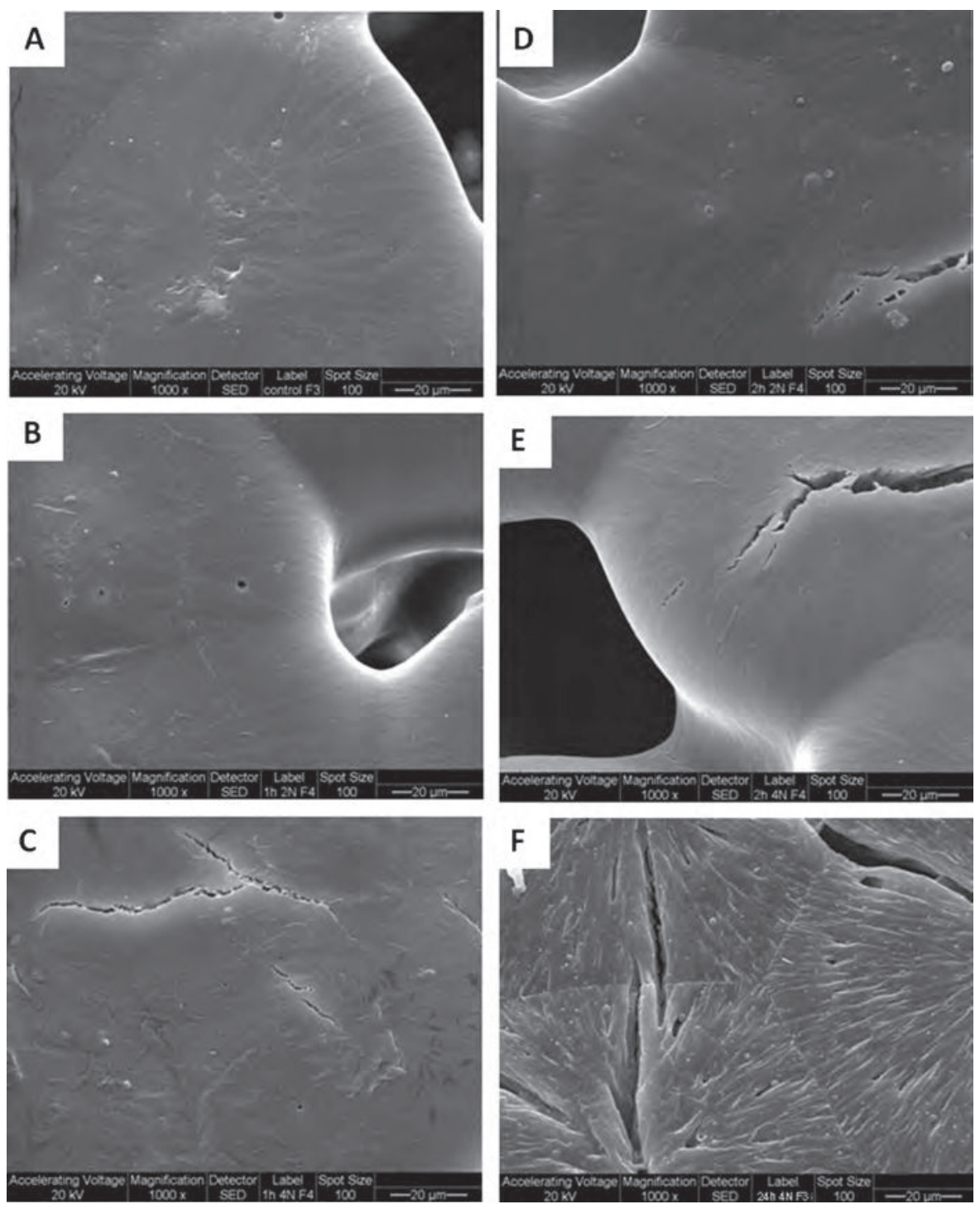

Fig. 1. SEM surface images $(1000 \times)$ of PCL scaffolds (A) after treatment with $1 \mathrm{H}-2 \mathrm{~N}(\mathrm{~B}), 1 \mathrm{H}-4 \mathrm{~N}(\mathrm{C}), 2 \mathrm{H}-2 \mathrm{~N}(\mathrm{D}), 2 \mathrm{H}-4 \mathrm{~N}(\mathrm{E})$ and $24 \mathrm{H}-4 \mathrm{~N}(\mathrm{~F})$.

treatments induced a significant increase in surface cracks when compared with control PCL (A). Long-term treatment with $\mathrm{NaOH}(\mathrm{F})$ increased the surface roughness of PCL. Thus, controlled alkaline treatment can modify scaffold topography, which might in theory affect its biocompatibility.

We also evaluated whether the different treatments could change the molecular weight and polydispersity of PCL, and only found significant differences for long-term treatments $(24 \mathrm{H}-4 \mathrm{~N}$ : lower $\mathrm{Mw}$ and higher PI versus untreated PCL) (Table I).

Although it is still not understood how the hydrophobicity or hydrophilicity of materials can regulate cellular activity and tissue regeneration, this is an important parameter to be considered when designing a scaffold since the initial interactions between cells and scaffolds are partly dependent on weak bonds such as dipole-dipole. ${ }^{20}$ Table I shows that the hydrophobicity of PCL decreases with the duration and intensity of $\mathrm{NaOH}$ treatment. Untreated PCL exhibited the highest WCA $\left(73.4^{\circ}\right)$. Although there was no difference between $1 \mathrm{H}-2 \mathrm{~N}\left(64.9^{\circ}\right)$ and $1 \mathrm{H}-4 \mathrm{~N}$ $\left(64^{\circ}\right)$, the WCA of PCL submitted to 2-hour treatments were lower than for 1-hour treatments. In addition, there was a significant difference between $2 \mathrm{H}-2 \mathrm{~N}\left(60.5^{\circ}\right)$ and

Table I. SEC, WCA and mechanical properties of PCL scaffolds after different alkaline treatments ( $\mathrm{n} / \mathrm{d}$ : not detectable).

\begin{tabular}{lcccc}
\hline Scaffold & Mw $\left(\mathrm{g} \mathrm{mol}^{-1}\right)$ & PI & WCA $\left(^{\circ}\right)$ & Elastic modulus (MPa) \\
\hline PCL & 65000 & 1.40 & $73.4 \pm 0.5$ & $152.28 \pm 10$ \\
$1 \mathrm{H}-2 \mathrm{~N}$ & 64967 & 1.41 & $64.9 \pm 0.4^{*}$ & $143.42 \pm 12$ \\
$1 \mathrm{H}-4 \mathrm{~N}$ & 65121 & 1.41 & $64.0 \pm 0.2^{*}$ & $146.59 \pm 16$ \\
$2 \mathrm{H}-2 \mathrm{~N}$ & 65051 & 1.38 & $60.5 \pm 0.3^{* \#}$ & $153.73 \pm 13$ \\
$2 \mathrm{H}-4 \mathrm{~N}$ & 64912 & 1.39 & $56.1 \pm 0.7^{* * \&}$ & $151.76 \pm 12$ \\
$24 \mathrm{H}-4 \mathrm{~N}$ & 51400 & 3.90 & $\mathrm{n} / \mathrm{d}$ & $\mathrm{n} / \mathrm{d}$ \\
\hline
\end{tabular}

Notes: ${ }^{*}: p<0.001$ versus PCL. ${ }^{\#}: p<0.05$ versus $1 \mathrm{H}$ group. ${ }^{\&}: p<0.01$ versus $2 \mathrm{H}-2 \mathrm{~N}$. 
$2 \mathrm{H}-4 \mathrm{~N}\left(56.1^{\circ}\right)$. Thus, the order of hydrophilicity was: PCL (control) $<1 \mathrm{H}-2 \mathrm{~N}=1 \mathrm{H}-4 \mathrm{~N}<2 \mathrm{H}-2 \mathrm{~N}<2 \mathrm{H}-4 \mathrm{~N}$; showing that the increase in hydrophilicity is directly dependent on the extent of corrosive treatment. However, after a 24hour treatment of PCL with $4 \mathrm{~N} \mathrm{NaOH}$, WCA was impossible to determine due to the instability of the water drop on the film. In agreement with our present results, Chen et al. found that a 3-hour treatment of PCL scaffolds with $5 \mathrm{~N} \mathrm{NaOH}$ (using 2-roll-heated-mill and biaxial stretching methods) significantly decreased the WCA of films. ${ }^{17}$
It is important to ensure that after being implanted the scaffold does not collapse, provides mechanical support and guides the repair of bone tissue. Table I shows the elastic moduli of PCL scaffolds before and after different treatments. The elastic modulus of our untreated PCL scaffolds was $152.28 \mathrm{MPa} \pm 10 \mathrm{Mpa}$, which is similar to that of mouse femur. ${ }^{30} 1$ - and 2-hour treatments with $\mathrm{NaOH}$ did not induce significant changes in the elastic modulus of PCL (around $150 \mathrm{MPa}$ ). However, 24 hours of exposure to $4 \mathrm{~N} \mathrm{NaOH}$ increased the fragility and breakability (a)

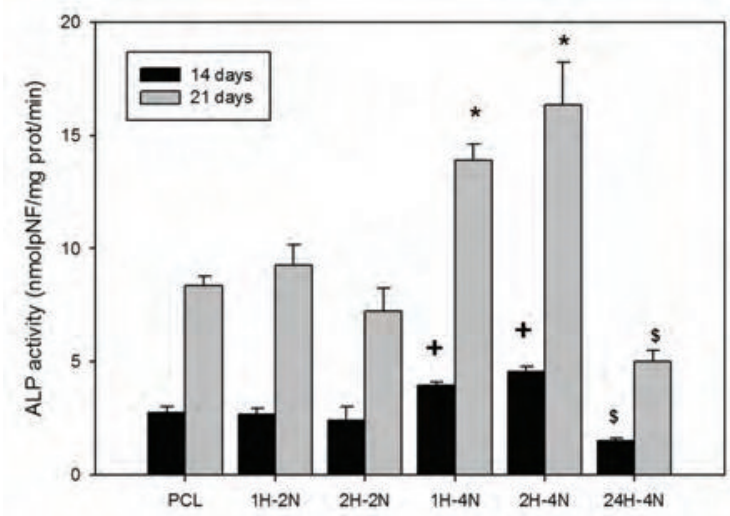

(b)
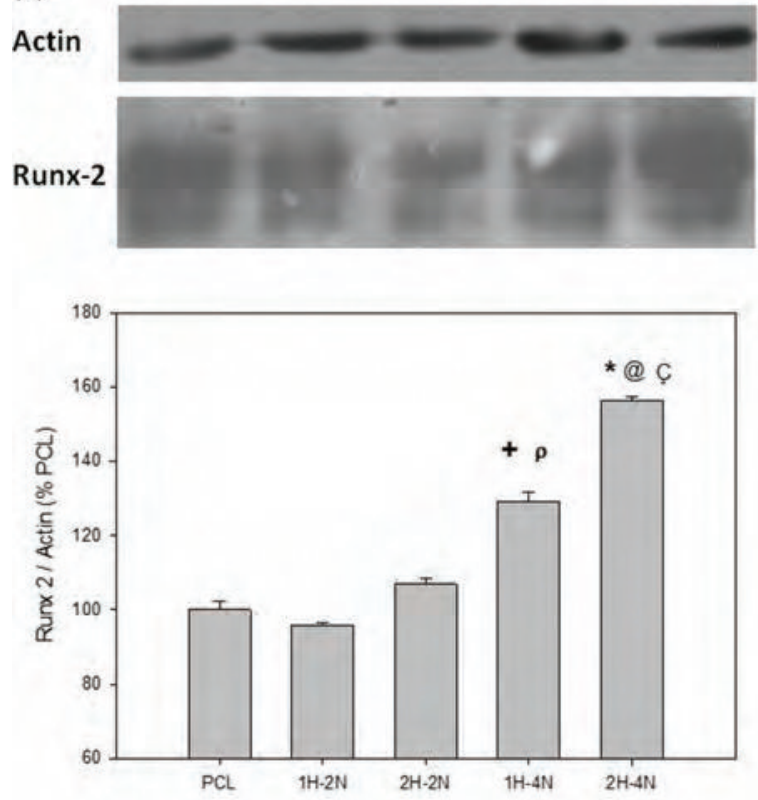

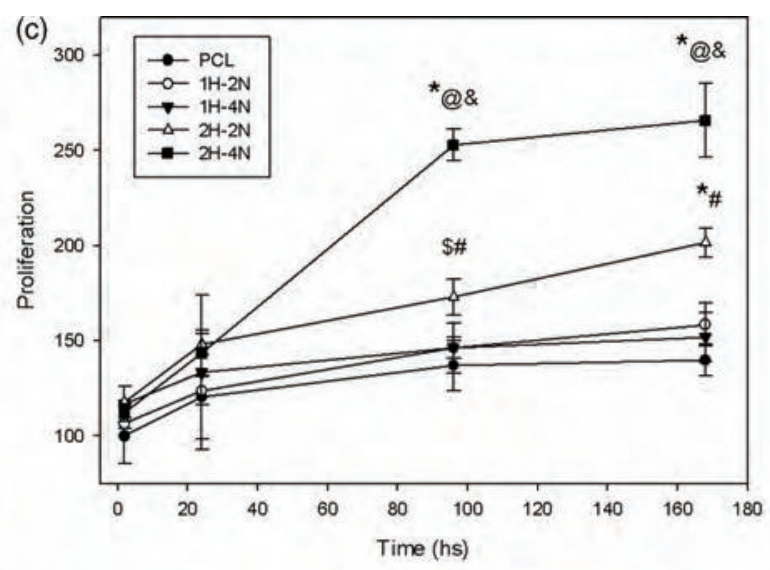

(d)

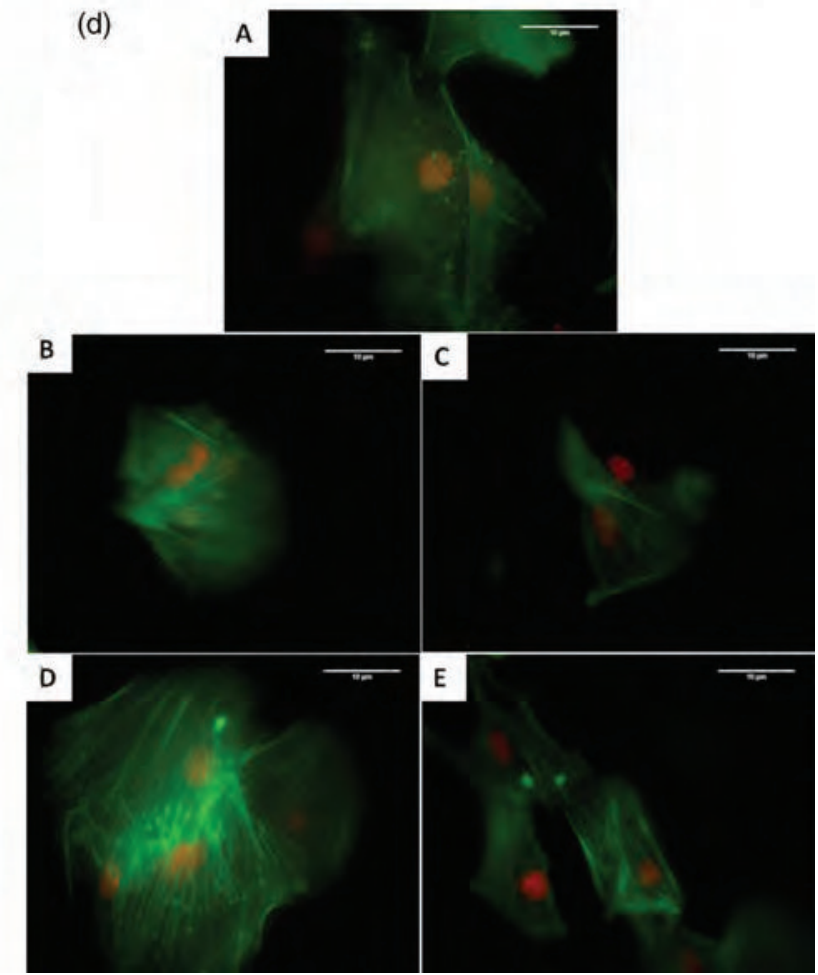

Fig. 2. (A) Alkaline Phosphatase activity of BMSC. ALP activity of BMSC extracts grown in an osteogenic medium for 14 and 21 days on different scaffolds. (B) RUNX-2 expression. Cells were plated on different scaffolds and cultured in an osteogenic medium for 3 weeks. The expression of Runx-2 and actin was evaluated by Western immunoblot. (C) BMSC proliferation using MTT assay. Values are expressed as $\%$ versus PCL after 2 hours of proliferation. $\$: p<0.05$ versus PCL; $+: p<0.01$ versus PCL; $*: p<0.001$ versus PCL; \#: $p<0.05$ versus 1 hour of treatment; @: $p<0.001$ versus 1 hour of treatment; $\rho: p<0.05$ versus 1 hour of treatment; $\&: p<0.01$ versus $2 \mathrm{H}-2 \mathrm{~N}$. C: $p<0.05$ versus $2 \mathrm{H}-2 \mathrm{~N}$ (D) cell morphology. Immunofluorescence for actin (green) and nucleus (red). (A) After treatment with $1 \mathrm{H}-2 \mathrm{~N}(\mathrm{~B}), 1 \mathrm{H}-4 \mathrm{~N}(\mathrm{C}), 2 \mathrm{H}-2 \mathrm{~N}(\mathrm{D}), 2 \mathrm{H}-4 \mathrm{~N}$ (E) scale bar: $10 \mu \mathrm{m}$. 
of PCL so much, that we could not determine these parameters.

Figure 2(A) shows the Alkaline Phosphatase activity (ALP) of BMSC grown on the treated and untreated scaffolds, after culturing in osteogenic medium for 2 or 3 weeks. The same patterns were seen for 14 and 21 days: ALP was similar to control (untreated PCL) in scaffolds treated with $2 \mathrm{~N} \mathrm{NaOH}$ for 1 or 2 hours, increased significantly with $1 \mathrm{H}-4 \mathrm{~N}$ and $2 \mathrm{H}-4 \mathrm{~N}$ PCL films, but greatly decreased with $24 \mathrm{H}-4 \mathrm{~N}$ scaffolds. Due to the high fragility of the $24 \mathrm{H}-4 \mathrm{~N}$ scaffolds, their reduced $\mathrm{Mw}$ and increased IP, to the impossibility of measuring WCA and their decreased biocompatibility for BMSC, they were studied no further.

We next evaluated by Western immunoblot whether the treated or untreated matrices differentially affected the expression of Cbfa1/Runx2, one of the major transcription factors for osteoblastogenesis. BMSC growing on different scaffolds were cultured in an osteogenic medium for 3 weeks. Figure 2(B) shows, in agreement with our results for ALP, that the expression of Runx2 was similar for BMSC grown on untreated PCL or on scaffolds modified by $2 \mathrm{~N} \mathrm{NaOH}$ for 1 or 2 hours; increased significantly for cells grown on matrices treated for 1 hour with $4 \mathrm{~N} \mathrm{NaOH}$; and increased even more for $2 \mathrm{H}-4 \mathrm{~N}$ films.

We also studied the attachment and proliferation of BMSC to the different matrices, using the MTT assay. As shown in Figure 2(C), after culturing for 2 hs BMSC adhered similarly to all scaffolds, and after 24 hs showed similar proliferation. However after $96 \mathrm{hs}, 2 \mathrm{H}-2 \mathrm{~N}$ and $2 \mathrm{H}-$ $4 \mathrm{~N}$ treatments increased BMSC proliferation versus control PCL $(\$: \mathrm{p}<0.052 \mathrm{H}-2 \mathrm{~N}$ vs. PCL and $*: p<0.0012 \mathrm{H}-4 \mathrm{~N}$ vs. PCL). In addition, BMSC proliferation increased both with the duration of alkaline treatment (\#: $p<0.05$ for $2 \mathrm{H}$ vs. $1 \mathrm{H}-2 \mathrm{~N}$ and $1 \mathrm{H}-4 \mathrm{~N})$ and with the concentration of $\mathrm{NaOH}$ used ( $\&$ : $p<0.01$ for $2 \mathrm{H}-4 \mathrm{~N}$ vs. $2 \mathrm{H}-2 \mathrm{~N}$ ). A similar pattern was observed after culturing BMSC on the same scaffolds for $168 \mathrm{hs:}$ a 2-hour alkaline treatment of the matrix (but not a 1-hour treatment) increased BMSC proliferation compared to control PCL. Gümüşderelioğlu et al. ${ }^{18}$ have shown that treatment of PCL with $\mathrm{NaOH}(5 \mathrm{H}-3 \mathrm{~N})$ decreases the proliferation of L929 and MDBK cells after 3, 5 and 7 days of culture. However, using the same alkaline treatment Chen et al. ${ }^{17}$ found that $\mathrm{NaOH}$ did not affect the proliferation of 3T3 cells after 3, 5 or 7 days of culture. In addition, Vance et al. ${ }^{19}$ demonstrated that $\mathrm{NaOH}$ treatment (1min-1N and 10 min-1N) of PCL decreased fibroblast proliferation versus control PCL after 5 days of culture.

In further experiments, we stained membrane-associated actin filaments (and nuclei) with specific fluorescent probes, in order to assess cellular interactions and morphology. Figure 2(D) shows that BMSC grown for 5 days on either control or $\mathrm{NaOH}$-treated PCL, adhere in a similar manner and present an extended morphology. This would indicate that the cells interact adequately with the different matrices, confirming that the membranes offer good support for cell growth.

As has been pointed out above, a very important requirement for biomaterials is that they must not be toxic since they have been designed for incorporation into a living organism. Previously, our group ${ }^{14,20}$ and
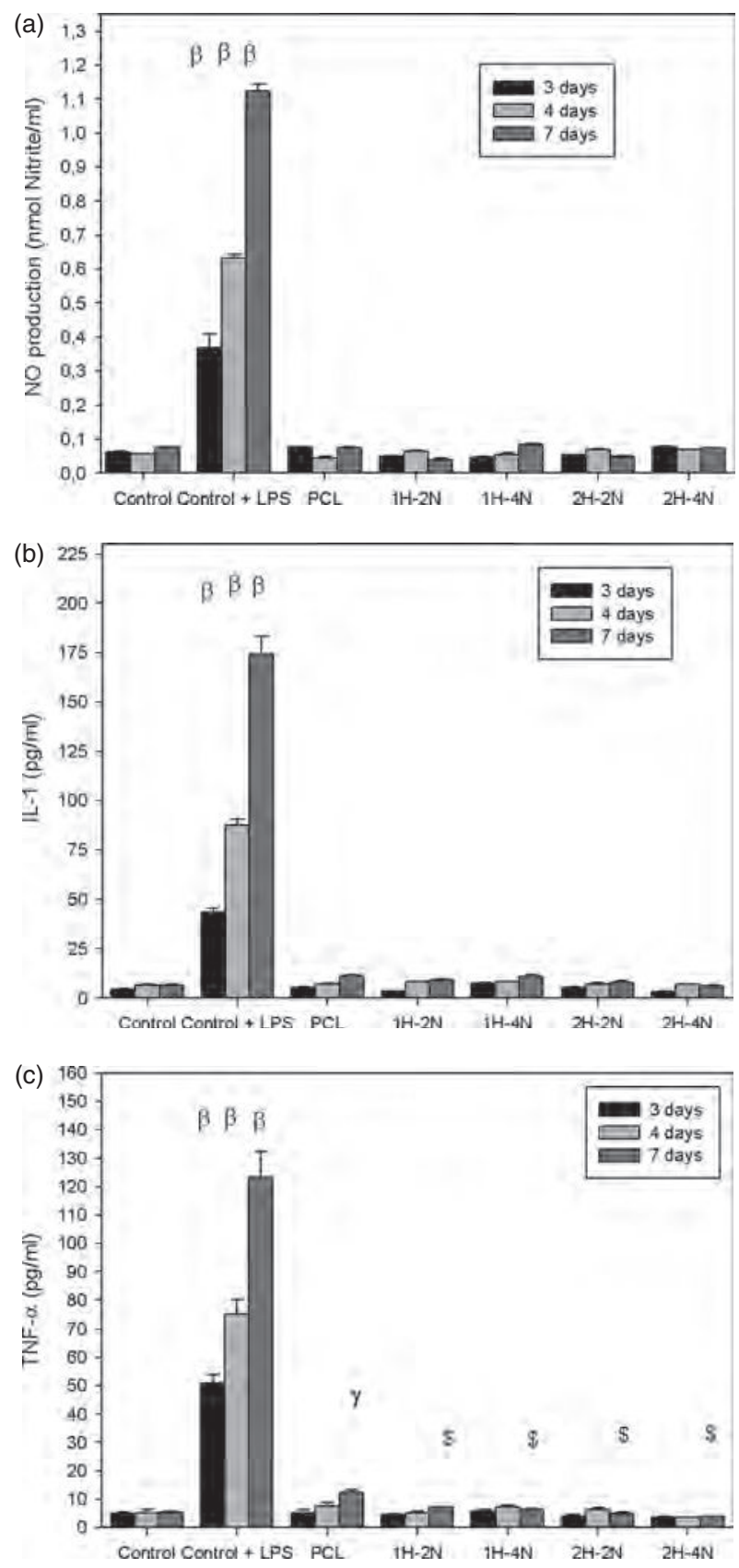

Fig. 3. Cytotoxicity studies. Levels of NO (A), IL-1 (B) and TNF- $\alpha$ (C) produced by RAW 264.7 macrophages cultured on standard plastic tissue culture dishes (control), control + LPS, PCL, $1 \mathrm{H}-2 \mathrm{~N}, 1 \mathrm{H}-4 \mathrm{~N}, 2 \mathrm{H}-2 \mathrm{~N}$ and $2 \mathrm{H}-4 \mathrm{~N}$. Except for LPS (positive control) and TNF- $\alpha$ secretion by RAW264.7 after 7 days culture on PCL, no significant differences were observed for the release of $\mathrm{NO}$ or secretion of cytokines in any other condition. As expected, LPS induced a significant increase in all proinflammatory markers. $\beta$ : $p<0.001$ versus control and scaffolds. $\$$ : $p<$ 0.05 versus PCL. $\gamma: p<0.05$ versus control. 
other researchers ${ }^{21-23}$ have shown that macrophages are a very sensitive culture model to evaluate possible in vitro inflammatory responses to a material with potential applications in tissue engineering. Therefore, the materials developed in our laboratory were evaluated to determine their potential cytotoxicity, assessing the release of NO and the pro-inflammatory cytokines TNF- $\alpha$ and IL- $1^{23}$ by macrophages cultured on the different materials for 3,4 and 7 days. Figure 3(A) shows that release of NO from cells grown on all evaluated polymers was similar to control (standard plastic tissue culture dish). When $0.1 \mathrm{~g} \cdot \mathrm{ml}^{-1}$ LPS was added to the culture medium as a positive control of cytotoxicity, a statistically significant $(\beta: p<0.001)$ increase in NO released to the culture media was detected. In addition, Figure 3(B) shows that there was no significant difference in the levels of IL-1 secreted into the culture medium between cells grown on the different polymeric scaffolds, or standard plastic tissue culture dishes. Again, in the presence of LPS cells responded by increasing the production of this cytokine after 3, 4 and 7 days of culture. A similar behaviour was observed for secretion of TNF- $\alpha$ (Fig. 3(C)), namely no significant differences between standard plastic tissue culture dishes and $\mathrm{NaOH}$-treated PCL matrices. Surprisingly, secretion of TNF- $\alpha$ increased significantly after culturing RAW 264.7 macrophages for 7 days on untreated PCL scaffolds. However, this increase was much lower than the levels of TNF- $\alpha$ induced by addition of LPS to the culture medium. We have previously evaluated $^{20}$ the cytotoxicity for RAW 264.7 macrophages of PCL (and of a compatibilized blend of PCL with polyfumarate), with and without hydroxiapatite. Although in those studies we found that PCL did not increase TNF- $\alpha$ secretion after 3 days of culture, longer-term (7-day) cultures were not evaluated.

\section{CONCLUSION}

We have evaluated the effect of different $\mathrm{NaOH}$ treatments on physicochemical and biological properties of PCL films obtained by casting methods. Controlled alkaline treatment of PCL induced:

(1) a more hydrophilic material with increased surface roughness;

(2) greater biocompatibility for bone marrow stromal cells; and

(3) lack of cytotoxicity for macrophages in culture.

In addition, we found that a 2 -hour treatment with $\mathrm{NaOH}$ was more effective than a 1-hour treatment in improving biocompatibility for bone-derived cells. Therefore, treatment for 2 hours with $\mathrm{NaOH}$ can be used to increase the biocompatibility of PCL scaffolds.

Acknowledgments: This work was partially supported by grants from Facultad de Ciencias Exactas, Universidad Nacional de La Plata (UNLP), Comisión de Investigaciones Científicas de la Provincia de Buenos Aires
(CICPBA) and Agencia Nacional de Promoción Científica y Tecnológica (Agencia). Juan Manuel Fernandez is a member of the carrer of Investigador Científico del CONICET.

\section{References and Notes}

1. M. Braddock, M. P. Houston, C. Campbell, and P. P. Ashcroft, Physiology 16, 208 (2001).

2. P. X. Ma, R. Zhang, G. Xiao, and R. Franceschi, Journal of Biomedical Materials Research 54, 284 (2001).

3. M. Morosano, A. Masoni, and A. Sánchez, Osteoporosis International 16, 1339 (2005).

4. J. R. Porter, T. T. Ruckh, and K. C. Popat, Biotechnol. Progr. 25, 1539 (2009).

5. R. Langer and J. Vacanti, Science 260, 920 (1993).

6. P. X. Ma, Mater. Today 7, 30 (2004).

7. M. S. Cortizo, M. S. Molinuevo, and A. M. Cortizo, Journal of Tissue Engineering and Regenerative Medicine 2, 33 (2008).

8. D. W. Hutmacher, Biomaterials 21, 2529 (2000).

9. V. Karageorgiou and D. Kaplan, Biomaterials 26, 5474 (2005).

10. X. Liu and P. X. Ma, Annals of Biomedical Engineering 32, 477 (2004).

11. E. L. Hedberg, C. K. Shih, J. J. Lemoine, M. D. Timmer, M. A. K. Liebschner, J. A. Jansen, and A. G. Mikos, Biomaterials 26, 3215 (2005).

12. M. A. Pattison, S. Wurster, T. J. Webster, and K. M. Haberstroh, Biomaterials 26, 2491 (2005).

13. M. C. Serrano, R. Pagani, M. Vallet-Regi, J. P. Comas, and M. T. Portoles, Acta Biomaterialia 5, 2045 (2009).

14. A. M. Cortizo, G. Ruderman, G. Correa, I. G. Mogilner, and E. J. Tolosa, J. Biomater. Tissue Eng. 2, 125 (2012).

15. J. M. Fernandez, M. S. Cortizo, A. M. Cortizo, and G. A. Abraham, J. Biomater. Tissue Eng. 1, 86 (2011).

16. P. S. Tan and S. H. Teoh, Mater. Sci. Eng. 27, 304 (2007).

17. F. Chen, C. N. Lee, and S. H. Teoh, Mater. Sci. Eng.: C 27, 325 (2007).

18. M. Gümüşderelioğlu, F. B. Kaya, and I. G. Beşkardeş, J. Colloid Interface Sci. 358, 444 (2011).

19. R. J. Vance, D. C. Miller, A. Thapa, K. M. Haberstroh, and T. J. Webster, Biomaterials 25, 2095 (2004).

20. J. M. Fernandez, M. S. Cortizo, and A. M. Cortizo, J. Biomater. Tissue Eng. 4, 227 (2014).

21. J. Bixby, T. D. Ray, and F. K. M. Chan, Current Medicinal Chemistry-Anti-Inflammatory and Anti-Allergy Agents 4, 557 (2005).

22. M. Blonska, Z. P. Czuba, and W. Krol, Scandinavian Journal of Immunology 57, 162 (2003).

23. L. C. Denlinger, P. L. Fisette, K. A. Garis, G. Kwon, A. VazquezTorres, A. D. Simon, B. Nguyen, R. A. Proctor, and P. J. Bertics, J. Biol. Chem. 271, 337 (1996).

24. M. S. Molinuevo, L. Schurman, A. D. McCarthy, A. M. Cortizo, M. J. Tolosa, M. V. Gangoiti, V. Arnol, and C. Sedlinsky, Journal of Bone and Mineral Research 25, 211 (2010).

25. A. M. Cortizo and S. B. Etcheverry, Mol. Cell Biochem. 145, 97 (1995).

26. M. M. Bradford, Anal. Biochem. 72, 248 (1976).

27. M. S. Molinuevo, S. B. Etcheverry, and A. M. Cortizo, Toxicology 210, 205 (2005).

28. V. C. Sálice, A. M. Cortizo, C. L. G. Dumm, and S. B. Etcheverry, Mol. Cell. Biochem. 198, 119 (1999).

29. A. M. Cortizo, M. Caporossi, G. Lettieri, and S. B. Etcheverry, Eur. J. Pharmacol. 400, 279 (2000).

30. W. G. Ding, S. D. Jiang, Y. H. Zhang, L. S. Jiang, and L. Y. Dai, Osteoporos Int. 22, 507 (2011).

Received: $x x$ Xxxx xxxx. Accepted: xx Xxxx xxxx. 